\title{
Age validation of age 0-3 wild cod Gadus morhua in the western Baltic Sea through mark-recapture and tetracycline marking of otoliths
}

\author{
Uwe Krumme $^{1, *}$, Sven Stötera ${ }^{1}$, Kate McQueen $^{1}$, Erhard Pahlke ${ }^{2}$ \\ ${ }^{1}$ Thünen Institute of Baltic Sea Fisheries, Alter Hafen Süd 2, 18069 Rostock, Germany \\ ${ }^{2}$ Fischereibetrieb Partenfischerei Gebrüder Erhardt \& Peter Pahlke, Königsberger Straße 2a, 23769 Fehmarn, \\ Ortsteil Burg, Germany
}

\begin{abstract}
The contrasting zones within otoliths are commonly used to infer age of fish, assuming that 1 opaque zone and 1 translucent zone (TZ) form per year. However, the periodicity of zone formation is often un-validated and susceptible to interpretation errors and uncertainties, which propagate into age-structured calculations. The western Baltic cod Gadus morhua (WBC) stock is currently evaluated through an age-based assessment, using the typical, temperate area assumption that TZs form in autumn/winter. The periodicity of zone formation was evaluated through a mark-recapture experiment with juvenile and young adult WBC. During 2014-2017, 9111 wild cod were tagged externally (T-bar anchor tag) and internally (injection with tetracyclinehydrochloride induced a permanent fluorescent mark on their otoliths) and released. Timing of TZ formation was reconstructed through examination of otoliths from recaptured age $0-3$ cod for which all required information and otoliths were available $(\mathrm{n}=59$, length range: $173-500 \mathrm{~mm})$. Contrary to the assumption that TZs are formed during winter, recaptured cod consistently formed $1 \mathrm{TZ}$ per year, between summer and autumn, in both juveniles (age 0-1) and young adults (age $2-3$ ). A calendar year in the otolith is therefore composed of a TZ with opaque material on either side. Coincidence of TZ formation and recent evidence of shallow-water avoidance and reduced feeding and growth in WBC during peak summer suggests that TZs are formed when metabolic demands cannot be met. The results improve accuracy of WBC age estimates and highlight the feasibility and importance of conducting age validation experiments.
\end{abstract}

KEY WORDS: Otolith · Tagging $\cdot$ Chemical marking $\cdot$ Mark-recapture experiment $\cdot$ Translucent summer ring $\cdot$ Age determination $\cdot$ Tetracycline

\section{INTRODUCTION}

Accurate age determination of fish is not only important to understand the life history of a population, but also to ensure the sustainable management of commercially exploited species (Beamish \& McFarlane 1983, Campana 2001). Age estimates form the basis for calculating many population demographics such as growth rates, mortality or year-class strength (Campana 2001).

Fish age is most commonly estimated by counting the annuli (i.e. the visible 'ring' structures, hereafter

${ }^{*}$ Corresponding author: uwe.krumme@thuenen.de referred to as 'zones') within otoliths (Kalish et al. 1995, Campana \& Thorrold 2001, Panfili et al. 2002). In temperate and subpolar fish, interpretation of alternating opaque and translucent growth zones within otoliths has been used as a method for age estimation for over $100 \mathrm{yr}$, assuming that 1 translucent and 1 opaque zone is formed during each year of life (Williams \& Bedford 1974). In many fish species, the ageing precision (i.e. repeatability) and/or accuracy (i.e. the closeness between the true and estimated age) may be limited, leading to large inconsistencies in age reading (e.g. Campana 2001, Hüssy et

() The authors 2020. Open Access under Creative Commons by Attribution Licence. Use, distribution and reproduction are unrestricted. Authors and original publication must be credited. 
al. 2016). This is particularly apparent in gadoid species, which comprise some of the largest demersal fish stocks in the North Atlantic. For example, de Pontual et al. (2006) found contrary seasonal patterns and additional non-periodical zones in the otoliths of European hake Merluccius merluccius in the Bay of Biscay, and ageing of eastern Baltic cod Gadus morhua using otoliths was recently found to be so imprecise that the age-based stock assessment for this stock was suspended for several years (Eero et al. 2015).

A major limitation of using annuli to determine age of wild fish is that the underlying mechanisms of zone formation are not completely understood (Beckman \& Wilson 1995, Panfili et al. 2002, Høie \& Folkvord 2006). The translucent zones in otoliths of temperate fish are often referred to as 'winter rings', as they are considered to be deposited during periods of slow growth in winter (or at colder temperatures) in temperate climatic regions (Beckman \& Wilson 1995), while the opaque zones have often been considered to be formed during faster growth in summer ('summer rings') (Pannella 1974). This pattern has also been reported for cod (Williams \& Bedford 1974), although exceptions do exist for different cod stocks (e.g. Dannevig 1956, Høie et al. 2009, Gjøsæter \& Danielssen 2011). Apparently, not only large variations in the seasonality of otolith zone formation exist (Beckman \& Wilson 1995, Høie et al. 2009, Fablet et al. 2011), but also regional differences in the timing of zone formation, even for stocks of the same species (Williams et al. 2005). Therefore, the prerequisite for age estimation via otoliths is the validation of the otolith growth zones for a population within its distribution area, in terms of both formation of the first zone, and the periodicity of the formation of all subsequent zones (Campana 2001).

Atlantic cod is a commercially important demersal cold-water species. Cod is found throughout the Atlantic, and its exploited habitat ranges into the North Sea and Baltic Sea (Robichaud \& Rose 2004, Drinkwater 2005). Temperatures in cod habitats range from -1.5 to $19^{\circ} \mathrm{C}$ (Blanchard et al. 2005, Righton et al. 2010, Freitas et al. 2016). The temperatures considered optimal for cod growth vary depending on life stage and fish size (Björnsson \& Steinarsson 2002), with the optimal temperature for growth of cod from certain populations determined experimentally to range between 6 and $17^{\circ} \mathrm{C}$ (Jobling 1988, Björnsson \& Steinarsson 2002).

The Baltic Sea is a brackish water region consisting of a series of basins of different depths separated by shallower sills, each basin having characteristic fea- tures. The region is divided into subdivisions (SDs) for management and stock assessment purposes (Regulation EC 218/2009; http://data.europa.eu/eli/ reg/2009/218/oj). The Baltic Sea is inhabited by 2 genetically distinct cod stocks: the western (WBC) and eastern (EBC) Baltic cod (Hemmer Hansen et al. 2019, Weist et al. 2019). While the demarcation of the zones within WBC otoliths is relatively clear, the clarity deteriorates eastwards (Stötera \& Krumme 2016).

The translucent zones (TZs) of WBC have been previously reported to form during autumn and winter (ICES 1994, 2000). Despite the clarity in zone demarcation, age interpretation inconsistencies have been documented for WBC. Age estimates for individual WBC otoliths have been repeatedly recorded to differ between age readers by up to $1 \mathrm{yr}$, mainly due to uncertainties in identifying the first TZ (ICES 2005, 2014). The age-based stock assessment of WBC was found to be sensitive to such age reading inconsistencies (ICES 2014). In general, age reading issues should be addressed to prevent errors and uncertainties propagating into stock assessments and other calculations reliant on age estimates. The timing and frequency of formation of the first TZs has recently been indirectly validated in juvenile WBC using a combination of length frequency and otolith edge type analysis, which revealed that the TZ forms during summer and autumn (McQueen et al. 2019a). This validation may have contributed to an apparent improvement in WBC age reading precision in recent years (ICES 2019a,b), though some inconsistencies and misinterpretations apparently remain (ICES 2019b) and different otolith preparation methods are still used (ICES 2019b). However, length frequency and otolith edge type analysis methods are generally unsuitable for the age validation of older individuals, and zone formation of juvenile fish should not by default be assumed to apply to adult fish (Campana 2001).

Validation of timing and periodicity of otolith annuli is essential to address the uncertainties in age reading of fish otoliths, and several established methods are available. Chemical marking and parallel external tagging of wild fish is an effective method to validate the timing of deposition of translucent and opaque zones that are formed in the otoliths between tagging and recapture, and to relate this to growth rates and movements (by recapture position information). Recapture experiments to validate the age reading of otoliths are rare, however, as they are considered costly and time-consuming, and, if carried out, are often restricted in terms of area covered and numbers tagged and returned (Beamish \& McFarlane 1983). It is possible to set up tagging experiments 
with limited effort and good recapture rates, e.g. by cooperating with local fishers in areas with high fishing pressure (from commercial and recreational fishers). The chemical marking of cod otoliths via intraperitoneal injection of tetracycline-hydrochloride generates a fluorescent band in the otolith that is easy to identify under a microscope using UV light (Stötera et al. 2019) and is still visible even decades after extraction and storage (Krumme \& Bingel 2016).

The objective of this study was to directly validate the timing and periodicity of $\mathrm{TZ}$ formation in markrecaptured $\mathrm{WBC}$, as an extension of the indirect age validation study of juvenile cod (age-0 to age-2) from the same region by McQueen et al. (2019a). We investigated whether a direct validation method confirms that juvenile cod in the western Baltic Sea form $1 \mathrm{TZ}$ per year during summer, and if these methods can reveal whether this zone formation pattern also holds true for adult cod in the region. Specifically, this study aimed to reveal whether the TZ is formed in winter (as commonly assumed for fish inhabiting temperate environments, Beckman \& Wilson 1995; and previously reported for WBC, ICES 1994, 2000) or during times of highest water temperature in summer/autumn (as indirectly shown for juvenile cod from the same area by McQueen et al. 2019a, and for cod in the North Sea by Pilling et al. 2007).

\section{MATERIALS AND METHODS}

\subsection{Study area}

The young cod used in this experiment were sampled from the Belt Sea ICES Subdivision 22 (SD22), around Fehmarn Island, Germany (Fig. 1). The Belt Sea receives the greatest exchange of higher salinity water originating from the Kattegat, and thermal

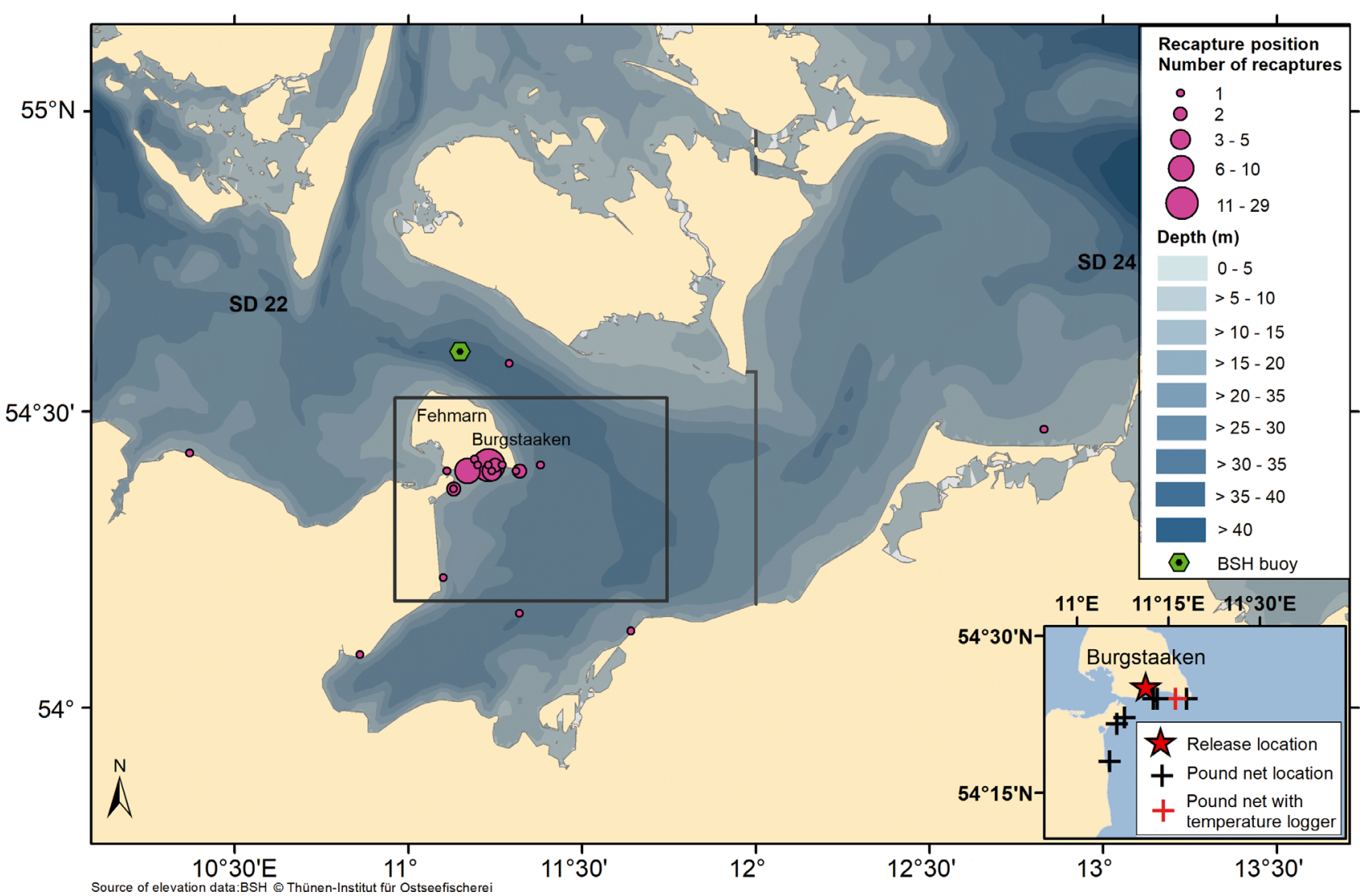

Fig. 1. Positions of cod recaptured between October 2014 and January 2018 in the western Baltic Sea. Points are graduated to reflect the number of cod recaptured at each location. In most cases, coordinates of recapture position were not available, and recapture position was estimated from available information on area of recapture (usually a place or area name). The border between ICES Subdivisions (SD) 22 and 24 is indicated by a grey line. Also indicated is the position of the German Federal Maritime and Hydrographic Agency (BSH) measurement buoy, where the temperature data displayed in Fig. 2 were recorded. Inset: positions of pound nets where cod were captured for tagging, and port of Burgstaaken where cod were tagged and released. The pound net where the temperature logger (data displayed in Fig. 2) was located is indicated 
convection regularly occurs in winter. The water temperature minimum in SD22 is usually reached in February, and the maximum in July/August (Fig. 2; Siegel \& Gerth 2015). To determine how the time period of TZ completion was correlated with water temperature, a HOBO Pro water temperature logger (Onset) recorded water temperature at least once every $6 \mathrm{~h}$ (starting at midnight) from September 2013 until April 2017. The sensor was installed at a fixed pillar of a pound net about $2 \mathrm{~m}$ below the water surface. Additionally, temperature data recorded at several depths in the water column from a measurement buoy in the nearby Fehmarn Belt (Figs. 1 \& 2) was provided by the Federal Maritime and Hydrographic Agency (Bundesamt für Seeschifffahrt und Hydrographie, BSH), from the German Oceanographic Data Center (Deutsches Ozeanographisches Datenzentrum, DOD). These data were used to illustrate the rela-

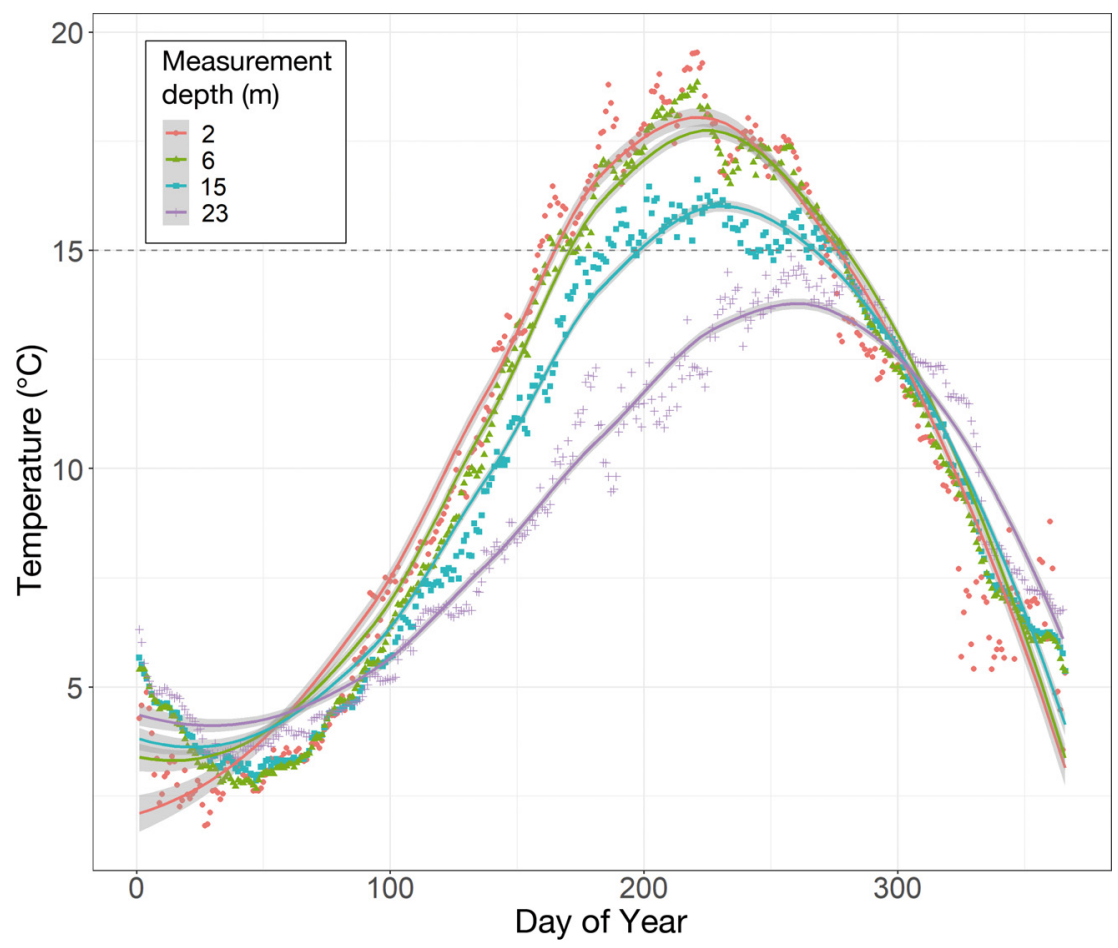

Fig. 2. Mean water temperature cycles recorded during the period 2013-2018 in the Fehmarn area, measured at approximately $2 \mathrm{~m}$ water depth by a logger attached to a pound net pillar, and at 6,15 and $23 \mathrm{~m}$ water depth by a measurement buoy of the German Federal Maritime and Hydrographic Agency $(\mathrm{BSH})$ in the Fehmarn Belt (locations indicated in Fig. 1). Frequency and periods of measurement varied slightly between the different depths (overview of measurement periods at different depths are shown in Fig. S3). Daily averages across the years are indicated by points, and a LOESS smoother (with grey shaded area indicating 95\% confidence interval) through these points indicates the overall trends. Temperatures above $15^{\circ} \mathrm{C}$ (indicated by dashed horizontal line) are generally considered above the thermal preference of cod, and may be above optimal for cod physiology (e.g. Jobling 1988, Björnsson \& Steinarsson 2002, Björnsson et al. 2007, Freitas et al. 2015) tionship between the temperature in the region at epths of 2, 6, 15 and $23 \mathrm{~m}$ (Fig. 2).

The surface salinity in the Belt Sea can vary between , mainly due to wind-driven hydrodynamics \& Jacobsen 1981, Siegel \& Gerth 2015). Oxygen saturation in water deeper than $20 \mathrm{~m}$ varies seasonally beeen 5\% (autumn) and 95\% (winter) (Hansson \& An2014) and is strongly influenced by periods of winter and major Baltic inflow events.

The spawning stock biomass of the WBC stock has been below the MSY $B_{\text {trigger }}$ reference point (a biomass nce point that triggers a cautious response within MSY [maximum sustainable yield] fram too high $\left(\mathrm{F}>\mathrm{F}_{\mathrm{MSY}}\right.$, where $\mathrm{F}$ is instantaneous rate of fishing mortality and $\mathrm{F}_{\mathrm{MSY}}$ is fishing mortality consistent with achieving maximum sustainable yield) since the 1980s (ICES 2019c). Between 2014 and 2019, only 1 strong year class occurred (in 2016), which dominates the relatively low catches (ICES 2019c).

\subsection{Tagging of cod}

A total of 9111 cod ranging from 11 to $48 \mathrm{~cm}$ total length (mean: $25 \mathrm{~cm}$ ) were injected with tetracycline, externally tagged and released between October 2014 and December 2017 in the port of Burgstaaken (Fig. 1). The fish were supplied by 2 commercial pound net fishers. The stationary uncovered pound nets were installed in shallow water ( $<5 \mathrm{~m}$ water depth) along the south coast of Fehmarn Island and the mainland proximities (SD22, Fig. 1) and targeted eel, larger cod and herring. Smaller cod are caught as bycatch. The nets were set perpendicular to the coastline, covering the entire water column; buoys at the head line and weights at the lead line forced fish to enter the catch chamber located at the seaward end (for details see McQueen et al. 2019a). The pound nets take advantage of the diel twilight migration of cod between daytime resting sites in deeper water and nightly feeding sites in structured shallow-water habitats (Burrows 
et al. 1994) which, around Fehmarn Island, are mainly seagrass Zostera marina beds. The catch chamber was stretched by ropes attached to fixed pillars. They were emptied every 1-17 d (mean 2.26 d) depending on weather conditions, during the fishing seasons. Therefore, most tagging was conducted between September-December and April-June, with occasional tagging taking place in January-February (Fig. 3).

Live cod were held in a flow-through tank on-board the fishing vessel and transported to the Port of Burgstaaken, where cod were kept in the harbour in floating fish boxes. Approximately weekly, all collected cod were marked and released. The fish were transferred to a bucket in groups of 6-10 individuals prior to tagging. The total length ( $\mathrm{mm}$ ) and wet mass $(\mathrm{g})$ of each fish was measured. Using a solution of $10 \mathrm{mg} \mathrm{ml}^{-1}$ tetracycline, $100 \mathrm{mg}$ tetracycline-hydrochloride per $\mathrm{kg}$ wet mass of cod was injected (Stötera et al. 2019). For injection, the cod were laid on their side and the head was covered with a damp cloth. Ventral injection (approximately at the end of the pelvic fin tips) penetrated only slightly and at a shallow angle into the body cavity to avoid damage to inner organs. Tetracycline is embedded into the otolith within approximately 24 h (Campana 2001, Panfili et al. 2002), creating a mark visible with a fluorescence microscope (Stötera et al. 2019). After injection, the fish were tagged externally with a coloured, uniquely numbered T-bar anchor tag (type TBF-1, Hallprint) about $1 \mathrm{~cm}$ below the first dorsal fin (for individual identification) and returned to the bucket (Fig. S1 in the Supplement at www.int-res.com/articles/suppl/m645p141_ supp.pdf). Injection and external tagging took approximately $30 \mathrm{~s}$ per fish. Once all fish from a bucket were tagged, they were released immediately or returned to the floating boxes and released together at

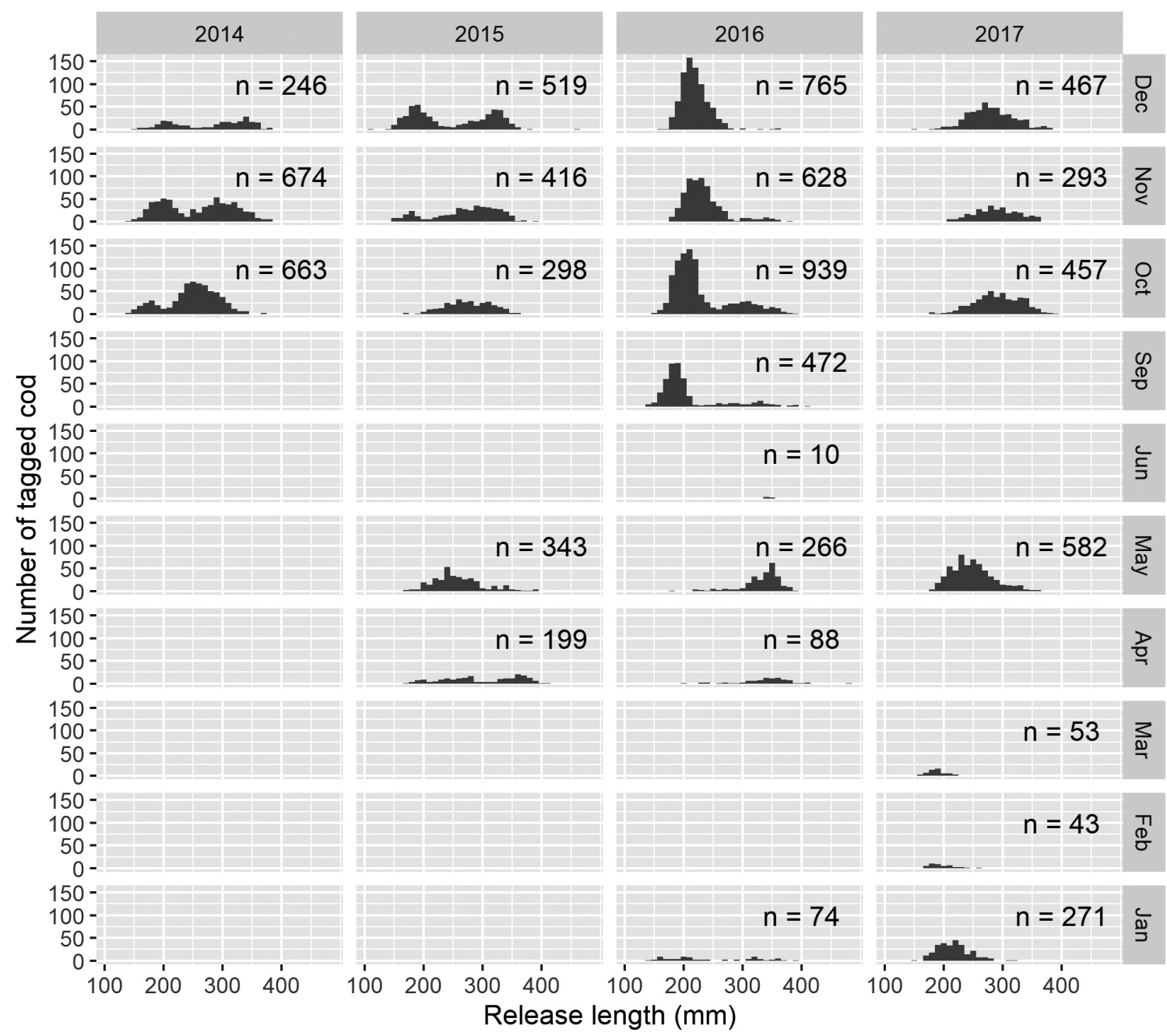

Fig. 3. Length frequencies of cod tagged between October 2014 and December 2017. Sample sizes of cod tagged per month (n) are indicated in each panel 
the end of the day. Tagged cod were released inside the Port of Burgstaaken to minimize predation by gulls and cormorants (Fig. S1). In addition, for most tagging events (69\%), a control group of 10-20 tagged cod was kept overnight to assess potential tag loss and short-term post-tagging mortality.

\subsection{Recaptured cod}

Recaptured cod were returned by commercial and recreational fishers, with information on time, location and gear type. A reward of $20 €$ for each whole returned cod was publicly announced upon the start of and during the experiment through letters to German captains of trawlers and larger gillnetters, posters at fishing associations and angler shops, and media articles (e.g. Fig. S1f). For each recapture, total length (to the nearest $\mathrm{mm}$ ) and weight (to the nearest g) were measured, and sex and maturity (10-stage maturity scale, Tomkiewicz et al. 2003) were determined. The sagittal otoliths were removed and stored dry and in darkness (wrapped in aluminium foil) to prevent fading of the fluorescent marks (Krumme \& Bingel 2016) until further processing.

\subsection{Otolith processing}

The sagittal otoliths of recaptured cod were embedded in epoxy resin (GTS polyester casting resin, Voss Chemie, 35-40\% styrene with MEKP-hardener). Embedded otoliths were thin sectioned across the nucleus (width of a section: $0.5 \mathrm{~mm}$ ), using a semiautomated mineralogy sawing machine (Brilliant 250, ATM). The otoliths were viewed under a microscope (Olympus BX60) and photographed with a digital camera (Zeiss Axiocam 105 colour). A photograph of each otolith section was taken with transmitted light, in the same way that images are captured for standard age reading procedures, to observe the opaque zones and TZs. To observe the fluorescent mark of the otoliths from recaptured cod, additional photographs were taken using an Olympus U-MNV filter cube (barrier filter: $455 \mathrm{~nm}$, excitation filter: 400-410 nm, dichroic mirror: $455 \mathrm{~nm}$ ).

\subsection{Otolith classification and validation of age reading method}

All 59 recaptured cod for which otoliths and recapture date were available were used in reconstructing
TZ formation. We classified each sectioned, recaptured otolith by referring to both the transmitted light image (used for standard age reading) and the UVlight images (used to visualise the location of the tetracycline mark). For illustrative purposes, the tetracycline filter image was made partially transparent and overlaid onto the transmitted light image, so that both opaque zones and TZs and the tetracycline mark could be seen (e.g. Fig. 4; Fig. S2). The following observations were recorded: (1) the edge type of the otolith (i.e. whether the incomplete zone at the outer edge of the otolith was opaque or translucent), (2) the type of zone containing the tetracycline mark (translucent or opaque), (3) the number of zone transitions between release and recapture (defined as the transition between opaque zone and TZ formation and vice versa) and (4) the number of completed TZs. The average (dorso-ventral) diameter of the first TZ reported by McQueen et al. (2019a) (2.0 $\pm 0.5 \mathrm{~mm})$ was used as a guide for identification of this zone, if required.

The zone containing the tetracycline mark can be considered the 'release zone', and the edge type can be considered the 'recapture zone'. Examination of the monthly distribution of the 'release zone type' and 'recapture zone type' provided information about the seasonality of zone formation. The number of zone changes between release and recapture provided information about the frequency of zone formation. In this study, we counted zone transitions instead of completed TZs between release and recapture because the majority of individuals were recaptured after less than 1 yr at liberty. We used these classifications to test the hypothesis that $1 \mathrm{TZ}$ forms per year, during the summer months. The following results would support this hypothesis: (1) translucent edge types would be present on otoliths recaptured during the summer, and opaque edge types would be present on otoliths recaptured during the winter; spring and autumn would be transition periods. (2) Likewise, cod released during the summer would have translucent release zone types, and cod released during the winter would have opaque release zone types. (3) In 1 year, we would expect no more than 2 zone changes, i.e. a change from opaque to translucent material in spring, and a change from translucent to opaque in autumn. (4) If these assumptions are confirmed, the counted completed TZs can be used to reliably estimate the age of the fish, with consideration of the edge type increasing the accuracy of age estimates.

The age-reading table for juvenile WBC presented in the supplementary material of McQueen et al. (2019a) was used to assign age to the recaptured cod, 


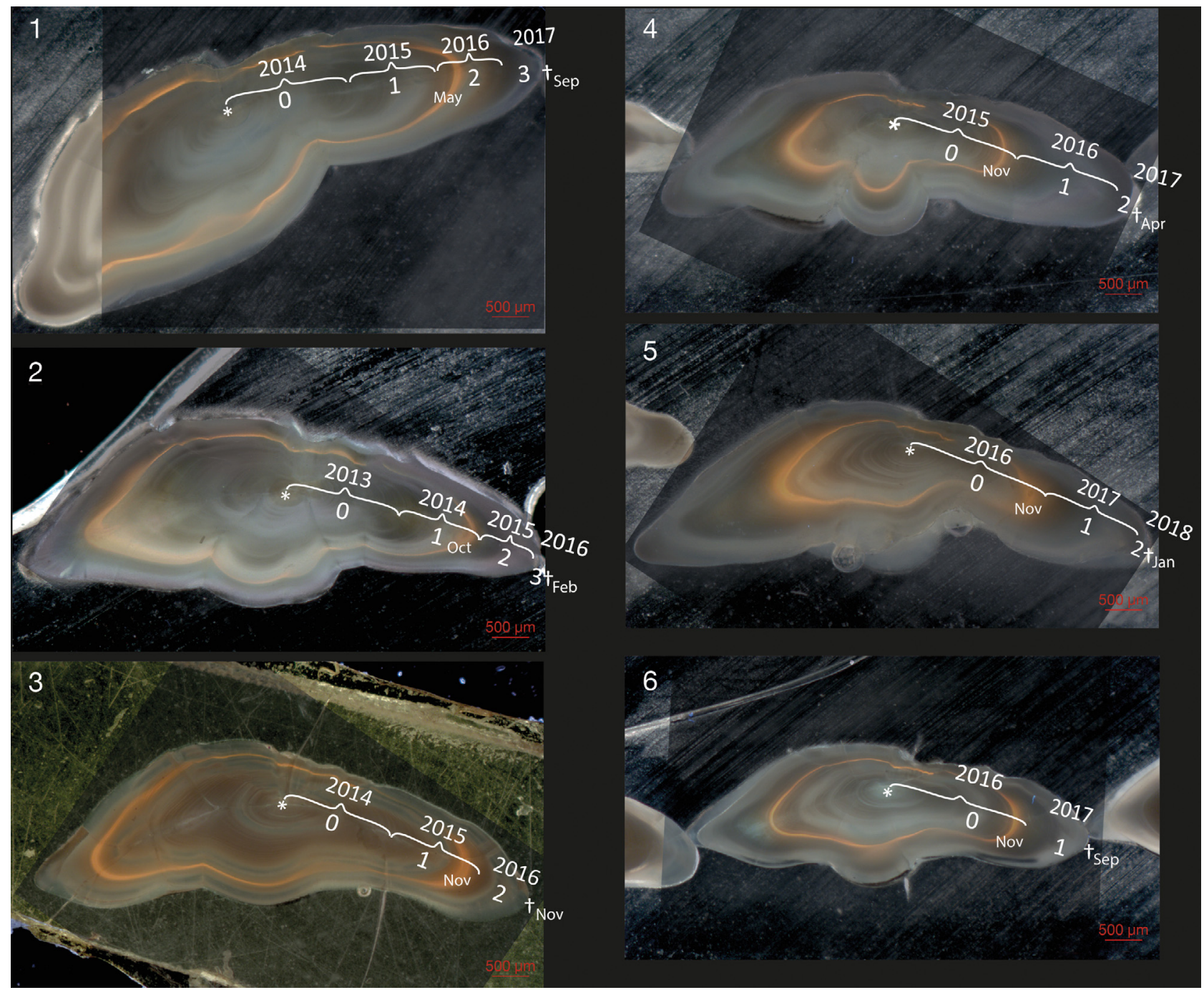

Fig. 4. Cross sections of 5 otoliths from fish at liberty for $\geq 11$ mo (1-5) and an example of a cod released as age-0 and recaptured as age-1 (6). An image of the otolith viewed using the tetracycline filter is overlaid onto an image of the otolith viewed using transmitted light. The overlaid tetracycline filter image has been made partially transparent so that the translucent and opaque zones of the otolith can also be seen. Brackets indicate an approximation of a year of otolith growth, consisting of a completed translucent zone with opaque material on either side. The years and the age are numbered along the axis from the core. Incomplete years at the edge are without a bracket. *: birth in spring, t: recapture or death. Month of release and recapture is indicated. For each otolith, further information is provided in Table 1

Table 1. Release, recapture and biological information from the 6 cod whose otoliths are displayed in Fig. 4. Release zone contains the tetracycline mark; recapture zone is classified by edge type. O: opaque, T: translucent. Zone transition: number of changes between opaque and translucent zones between release and recapture. Dates are given as d.mo.yr; -: missing information; Maturity: measure using the 10-stage maturity scale (Tomkiewicz et al. 2003)

\begin{tabular}{|c|c|c|c|c|c|c|c|c|c|c|c|}
\hline \multirow{2}{*}{$\begin{array}{l}\text { Otolith } \\
\text { ID }\end{array}$} & \multirow[b]{2}{*}{ Date } & \multicolumn{2}{|c|}{ - Release } & \multicolumn{2}{|c|}{ — Time at liberty —— } & \multirow[b]{2}{*}{ Date } & \multirow[b]{2}{*}{ Zone } & \multirow{2}{*}{$\begin{array}{l}\text { Recapture } \\
\text { Length (mm) }\end{array}$} & \multirow{2}{*}{ Age } & \multirow[b]{2}{*}{ Sex } & \multirow[b]{2}{*}{ Maturity } \\
\hline & & Zone & Length (mm) & Months & Zone transitions & & & & & & \\
\hline 1 & 03.05 .2016 & $\mathrm{O}$ & 355 & 17 & 3 & 29.09 .2017 & $7 \mathrm{~T}$ & - & 3 & - & - \\
\hline 2 & 24.10 .2014 & $\mathrm{O}$ & 330 & 15 & 1 & 01.02 .2016 & $\mathrm{~T}$ & 470 & 3 & $\mathrm{~F}$ & - \\
\hline 3 & 23.11 .2015 & $5 \mathrm{O}$ & 312 & 12 & 1 & 13.11 .2016 & $\mathrm{~T}$ & 430 & 2 & - & - \\
\hline 4 & 23.11 .2015 & $\mathrm{O}$ & 166 & 17 & 2 & 20.04 .2017 & $7 \mathrm{O}$ & - & 2 & - & - \\
\hline 5 & 03.11 .2016 & $\mathrm{O}$ & 205 & 14 & 2 & 18.01.2018 & $3 \mathrm{O}$ & 492 & 2 & M & $\mathrm{V}$ \\
\hline 6 & 24.11 .2016 & $\mathrm{O}$ & 216 & 10 & 1 & 29.09 .2017 & $7 \mathrm{~T}$ & - & 1 & - & - \\
\hline
\end{tabular}


through consideration of month of capture, number of completed TZs and outer edge classification of the otolith. An artificial birthday of 1 January was assumed for all fish, following standard age-reading protocols for WBC. This age-reading table can be used to age WBC of 0-2 yr old, i.e. which have up to 2 completed TZs in the otolith. Three recaptured individuals were older than the ages covered in this table ( 3 completed TZs at recapture). They were assigned an age by assuming the relationship between edge type and month was the same as for younger individuals (i.e. applying the same rules as for an individual with $2 \mathrm{TZs}$, but adding $1 \mathrm{yr}$ ). This assumption, and the assumptions underlying the age-reading table of McQueen et al. (2019a), were tested using the otolith classifications and hypothesis testing described above.

An additional exercise was carried out to assess whether edge analysis is an effective method for characterising timing of zone formation for young adult cod from the western Baltic Sea. For this exercise, the Thünen Institute of Baltic Sea Fisheries database of samples from the German commercial fisheries was searched for cod between 30 and $40 \mathrm{~cm}$ total length, captured by trawl, gillnet or pound net throughout SD22 in 2014 or 2015. The otoliths had already been sectioned and photographed following standard procedures as preparation for routine age reading. These otolith images were re-examined, and the edge types were classified as either opaque or translucent (for more details see Fig. S8). The timing of $\mathrm{TZ}$ formation estimated via this method was compared with the results from recaptured, chemically marked cod.

\subsection{Individual growth rate estimation}

To assess whether the released cod grew as expected for cod in the region, the time at liberty and change in length between tagging and recapture was used to estimate the growth per day of each recaptured individual, and to estimate average growth of recaptures in $\mathrm{cm}$ per year. The growth of individuals was compared with standardised, average monthly length frequencies compiled from regular sampling from the pound nets during 2013-2016, which have indicated the presence of 2 cohorts of juvenile cod present in the area (McQueen et al. 2019a). The length frequencies have been used previously to estimate growth and to validate age of juvenile WBC, and the sampling and standardisation procedures are described in previous publications (McQueen et al. 2019a,b).

\section{RESULTS}

\subsection{Water temperature}

Average daily water temperature at the pound net ( $2 \mathrm{~m}$ depth) during the study period ranged from $1.8^{\circ} \mathrm{C}$ in January to $19.5^{\circ} \mathrm{C}$ in August (mean: $10.4^{\circ} \mathrm{C}$ ). The temperature profile followed a similar pattern each year, reaching temperatures above $15^{\circ} \mathrm{C}$ between mid-June and mid-September (Fig. 2; Fig. S3). The temperature recorded at deeper depths offshore in the Fehmarn Belt also followed a similar pattern, but with temperature attenuation with depth, particularly noticeable as a delayed and diminished peak at $23 \mathrm{~m}$ depth (Fig. 2; Fig. S3).

\subsection{Tagged cod}

No tag loss was observed from the control groups of tagged cod. Total short-term post-tagging mortality rate during 2014-2017 was 5\%.

\subsection{Recaptured cod}

By January 2018, 73 recaptured cod had been reported, corresponding to a reporting rate of $0.8 \%$. Of these recaptured cod, 13 could not be used for age validation, as the whole cod was not returned and otoliths were unavailable. Of the 60 remaining recaptures, one was excluded from analysis, as reliable recapture information was not provided.

Of the recaptures, $33(45 \%)$ were reported by the pound net fishers involved in the tagging activities, $35(49 \%)$ were reported by other fishers operating in the area around Fehmarn, and only 5 (7\%) were reported from further afield (>35 km from Fehmarn, Fig. 1). The returned cod not recaptured in the pound nets were caught either by gillnetting ( $\mathrm{n}=21$ ), angling (12), in eel pots (6) or by trawling (1).

The shortest recapture period was $5 \mathrm{~d}$ after release (tagged in November 2015), the longest was $835 \mathrm{~d}$ (tagged in October 2014, no otolith available), and average time at liberty was $173 \mathrm{~d}$. Cod were recaptured throughout the year, but the highest numbers were recaptured in June $(\mathrm{n}=19)$ and November (n = 17).

The sex and maturity of 37 recaptured cod could be determined. Some recaptures were returned already gutted, so sex and maturity could not be assigned. Most of the recaptured cod were female ( $\mathrm{n}=25$, $69 \%)$, and 12 were male (31\%). Two males and 


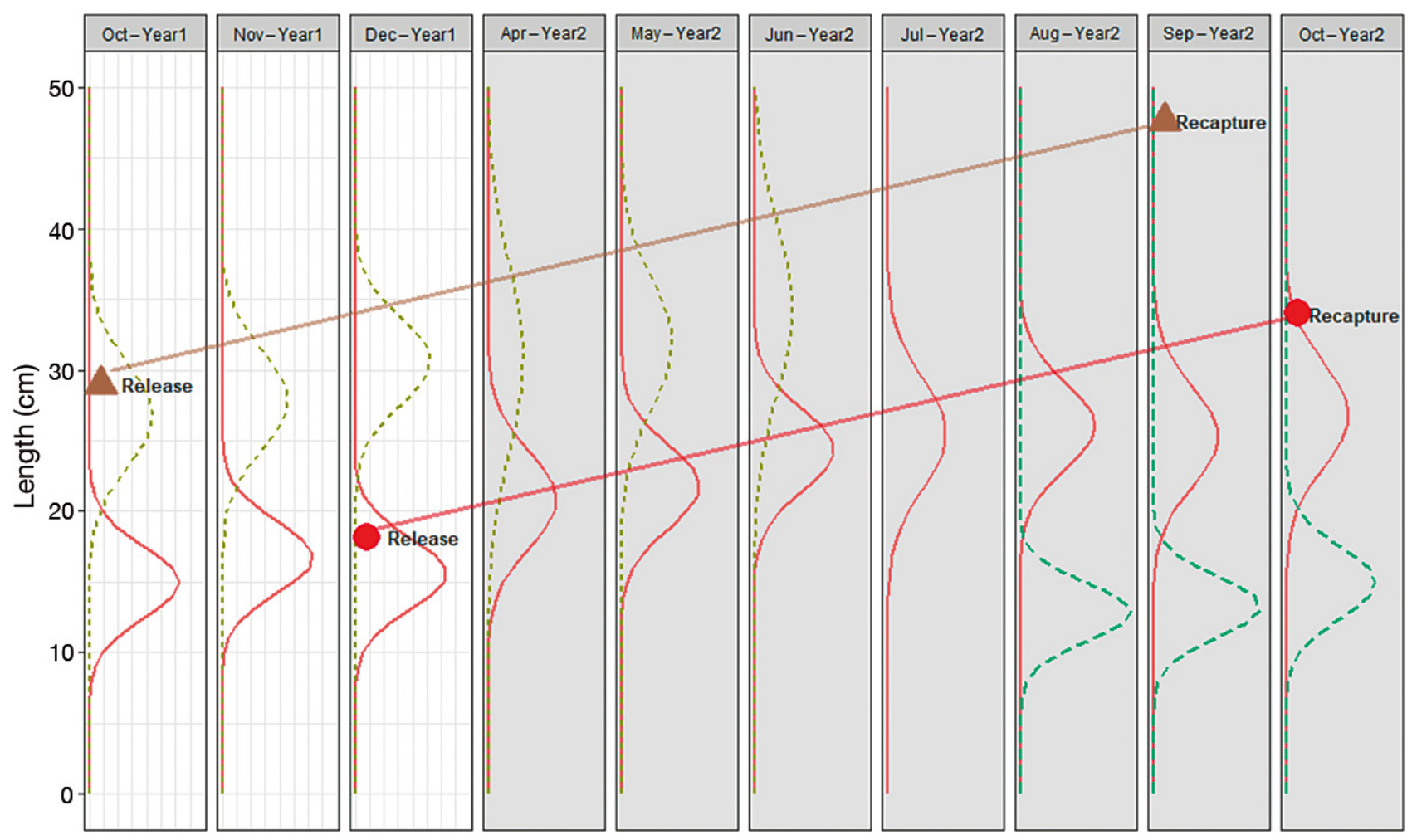

Fig. 5. Release and recapture lengths for 2 recaptured cod, recaptured the year following release (red circle: tagged as age-0 cod, otolith ID 1; brown triangle: tagged as age-1, otolith ID 2), connected by a line to illustrate their growth through the monthly modes of their respective cohorts. Normal distributions were estimated from standardised average length frequency distributions sampled from pound nets during 2013-2016 (McQueen et al. 2019a). In Year 1 (year of release), the age-0 cohort is indicated by a red solid line, and the age-1 cohort by a brown dashed line. In Year 2 (year of recapture) the age-1 cohort is indicated by a red solid line, the age- 2 cohort by a brown dashed line, and the new age- 0 cohort as a green dashed line. Average abundances of each cohort present in the pound nets are not shown here, only the average shape of the distributions. Average normal distributions could only be estimated for April-December, due to a lack of data for January-March. Otoliths (including the tetracycline mark) and biological data of the 2 cod are shown in Fig. 6 and Table 2, respectively

Table 2. Individual fish data for the 2 cod referred to in Figs. 5 \& 6; other details as in Table 1

\begin{tabular}{|c|c|c|c|c|c|c|c|c|c|c|c|}
\hline \multirow{2}{*}{$\begin{array}{l}\text { Otolith } \\
\text { ID }\end{array}$} & \multirow[b]{2}{*}{ Date } & \multicolumn{2}{|c|}{ Release } & \multicolumn{2}{|c|}{ — Time at liberty — } & \multirow[b]{2}{*}{ Date } & \multirow[b]{2}{*}{ Zone } & \multirow{2}{*}{$\begin{array}{l}\text { - Recapture } \\
\text { Length (mm) }\end{array}$} & \multirow{2}{*}{ Age } & \multirow[b]{2}{*}{ Sex } & \multirow[b]{2}{*}{ Maturity } \\
\hline & & Zone & Length (mm) & Months & Zone transitions & & & & & & \\
\hline 1 & 07.12 .2016 & $\mathrm{O}$ & 182 & 10 & 1 & 06.10 .2017 & $\mathrm{~T}$ & 340 & 2 & M & V \\
\hline 2 & 24.10 .2014 & $\mathrm{~T}$ & 290 & 11 & 2 & 22.09 .2015 & $\mathrm{~T}$ & 476 & 2 & $\mathrm{~F}$ & II \\
\hline
\end{tabular}

1 female, with lengths of 173-205 mm, were classified as immature (maturity stage I). The majority of recaptures $(68 \%)$ were classified as in the first preparation stage (maturity stage II), including both males (6) and females (17) with lengths ranging from 193-476 mm. Nine individuals (6 females and 3 males), with lengths ranging from 240-492 mm were classified as mature (maturity stages III-VIII).

The connection of the length at release and length at recapture suggests that the 3 length frequency modes present at this sampling site represent different age groups, as the assumed linear growth tra- jectory of individuals follows the progression of the length frequency modes without crossing into another of the modes (Figs. $5 \& 6$ ).

Several negative growth rates were recorded for fish at liberty for short time periods (22\%, Fig. S4). This may be due to the fact that many recaptures $(55 \%)$ were frozen before length measurements were taken and post-mortem shrinkage may have occurred. Excluding individuals with short times at liberty ( $<50$ d, Fig. S4), the average growth rate of the recaptured cod was $15.25 \mathrm{~cm} \mathrm{yr}^{-1}$ (range: 3.7-37 $\mathrm{cm} \mathrm{yr}^{-1}$; $\mathrm{n}=36)$. 


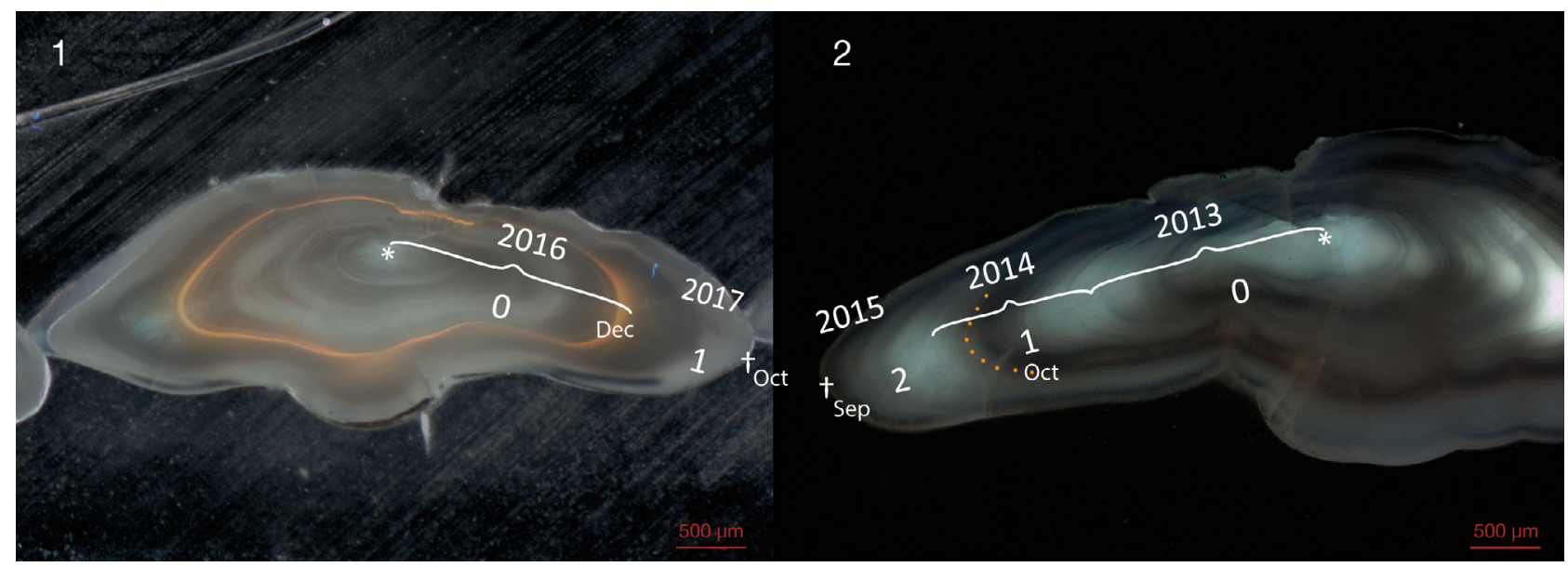

Fig. 6. Otoliths from cod plotted in Fig. 5, to exemplify the cohort growth rates. Otolith 1: cod released as age-0 and recaptured as age-1. Otolith 2: cod released as age-1 and recaptured as age-2. Otolith 1: image was viewed using the tetracycline filter overlaid onto an image of the otolith viewed using reflected light. The overlaid tetracycline filter image has been made partially transparent so that the translucent and opaque zones of the otolith can also be seen. Otolith 2: section was polished to a thickness of ca. $100 \mu \mathrm{m}$ before photographing; therefore, due to the thinness of this section, the macrostructure of the otolith and the tetracycline mark can both be seen in the tetracycline filter image of this otolith, without requiring any image editing (orange dots indicate the tetracycline mark). The image was taken using the tetracycline filter and a minimal amount of transmitted light, so the opaque zones appear light and the translucent zones darker. Otolith interpretation is illustrated using the overlaid symbols following the description in Fig. 4. Individual fish data are presented in Table 2

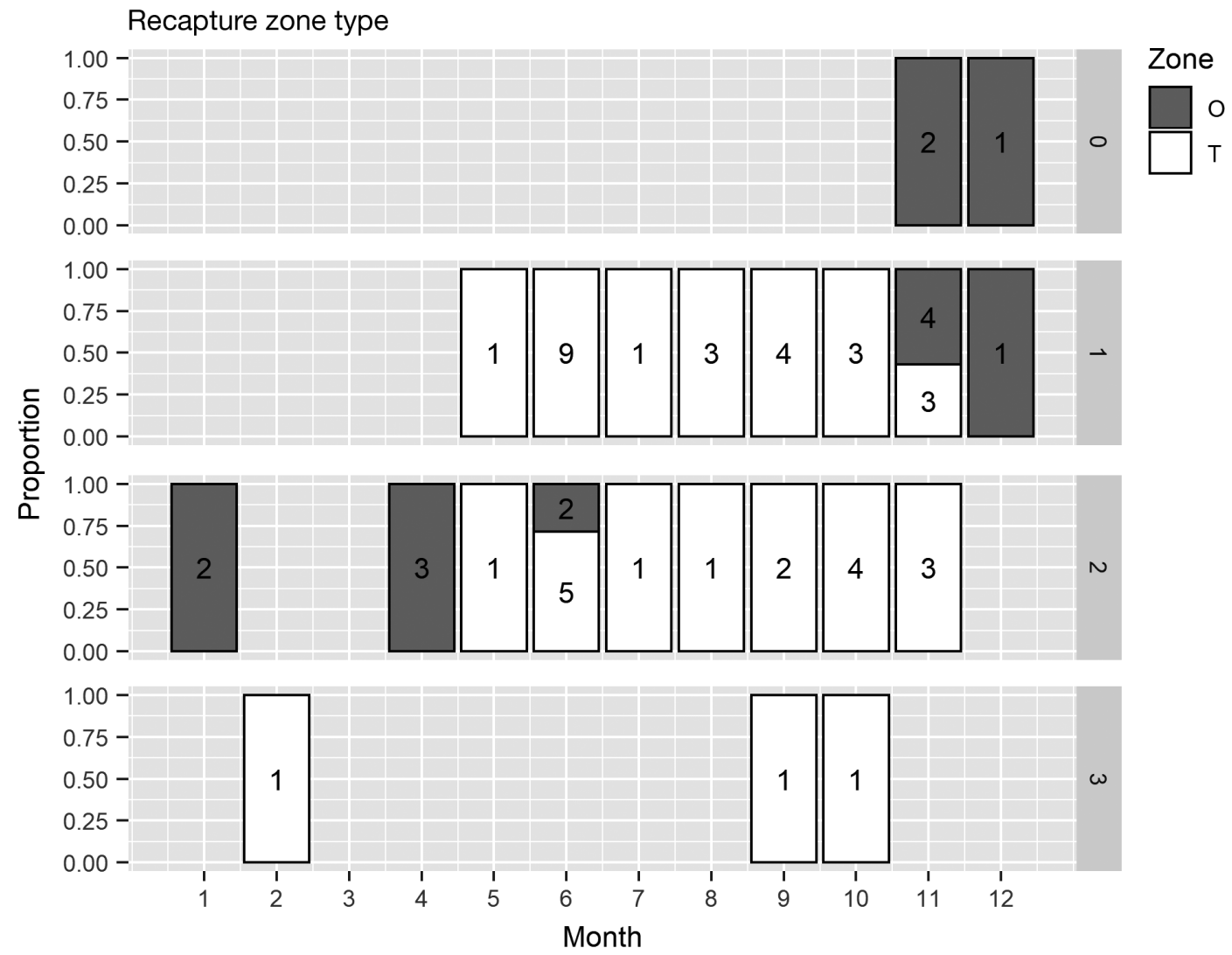

Fig. 7. Proportions of recaptured cod recaptured during opaque $(\mathrm{O})$ and translucent $(\mathrm{T})$ zone formation per month, identified by otolith edge type. Sample size is indicated within the bars. Data are split by age at recapture (rows) 


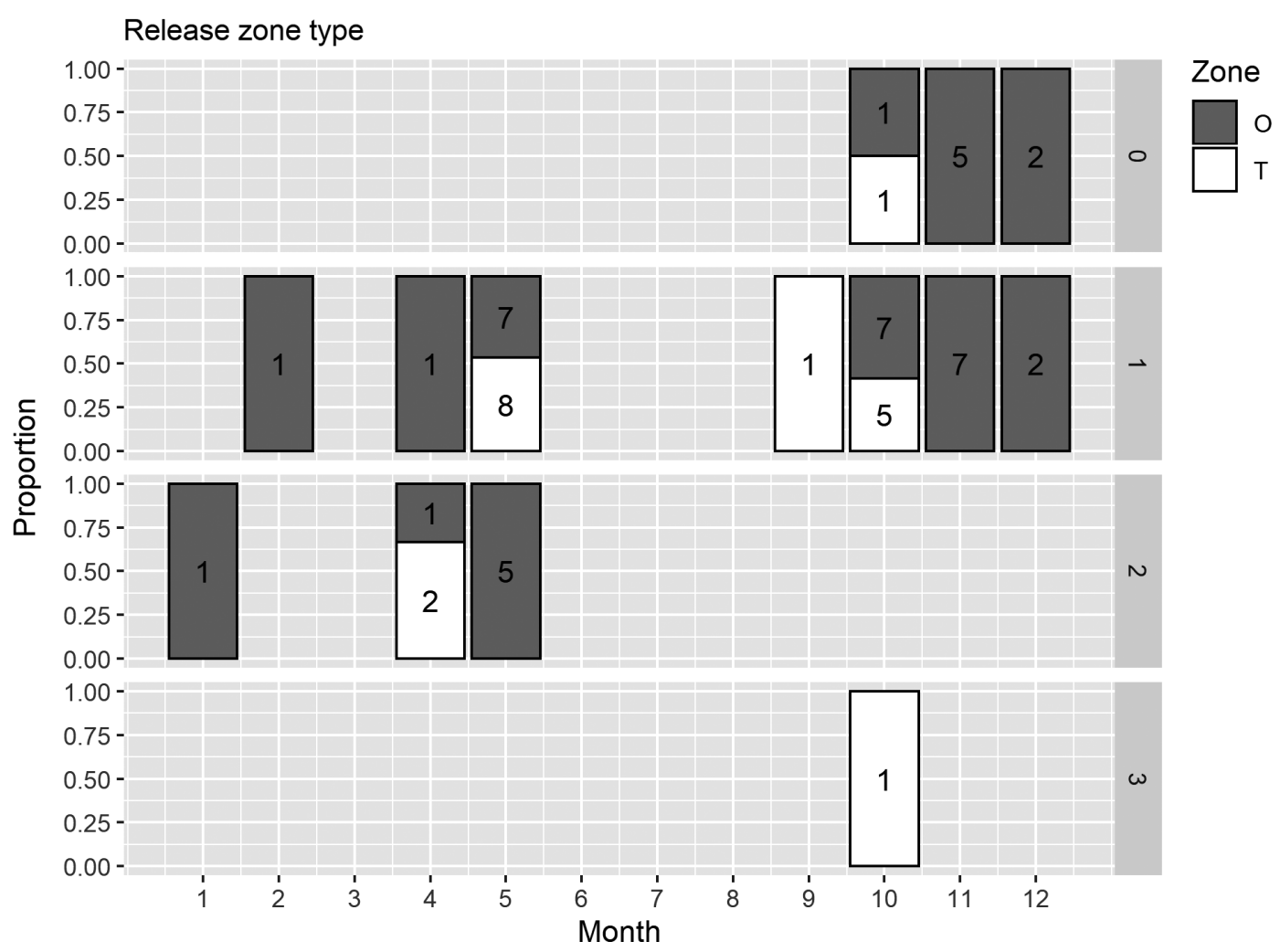

Fig. 8. Proportions of recaptured cod tagged during opaque $(\mathrm{O})$ and translucent $(\mathrm{T})$ zone formation per month, identified by the zone containing the tetracycline mark. Sample size is indicated within the bars. Data are split by age at release calculated from the age at recapture (rows)

\subsection{Otolith classification and validation of age reading method}

The tetracycline mark was clearly visible in all available recaptured cod otoliths. Classification of the otoliths revealed the following:

(1) Most otoliths from cod recaptured between May and October had translucent edge types $(n=37)$, and most of those recaptured between December and April had opaque edge types $(n=7)$. Of the $12 \mathrm{cod}$ recaptured in November, 6 had opaque and 6 had translucent edge types. Exceptions to this pattern are an individual recaptured in February with a translucent edge type and 2 individuals recaptured in June with an opaque edge type (Fig. 7).

(2) The release zone type of the 2 cod released in January and February was opaque. In April and May, the release zone type was either opaque $(n=$ $15)$ or translucent $(n=10)$. The only recaptured cod released in September had a translucent release zone type. In October, the release zone type was either translucent $(n=7)$ or opaque $(n=9)$. In November and December, the release zone type was opaque $(\mathrm{n}=16)$ (Fig. 8). Overall proportions of edge type at release and recapture are given in
Fig. S5. Additional example otolith images of cod tagged during opaque and TZ formation are given in Figs. S6 \& S7 (with single fish data in Tables S1 \& S2), respectively.

(3) For the majority of recaptured cod, the number of zone transitions which occurred between release and recapture does not contradict the hypothesis that $1 \mathrm{TZ}$ and 1 opaque zone forms during $1 \mathrm{yr}$ of life. The majority of recaptures had less than $1 \mathrm{yr}$ at liberty $(n=54)$ and almost all of these had $0(n=26)$ or only $1(\mathrm{n}=25)$ zone transition during this period, with 3 individuals displaying 2 zone transitions (Fig. 9). Five individuals were at liberty for more than $1 \mathrm{yr}$. Two of these had 2 zone transitions and 1 fish had 3, which does not contradict the hypothesis. However, 2 individuals had only 1 zone transition, which is not in line with the hypothesis of 2 zone transitions per year (Fig. 9).

(4) The majority of recaptures had either $1(n=27)$ or $2(\mathrm{n}=30)$ completed $\mathrm{TZs}$, and 2 recaptures had $3 \mathrm{TZs}$.

Apart from the few exceptions outlined above, the majority of otolith classification results did not contradict the zone formation hypothesis outlined in Section 2.5. Consequently, a calendar year in WBC 


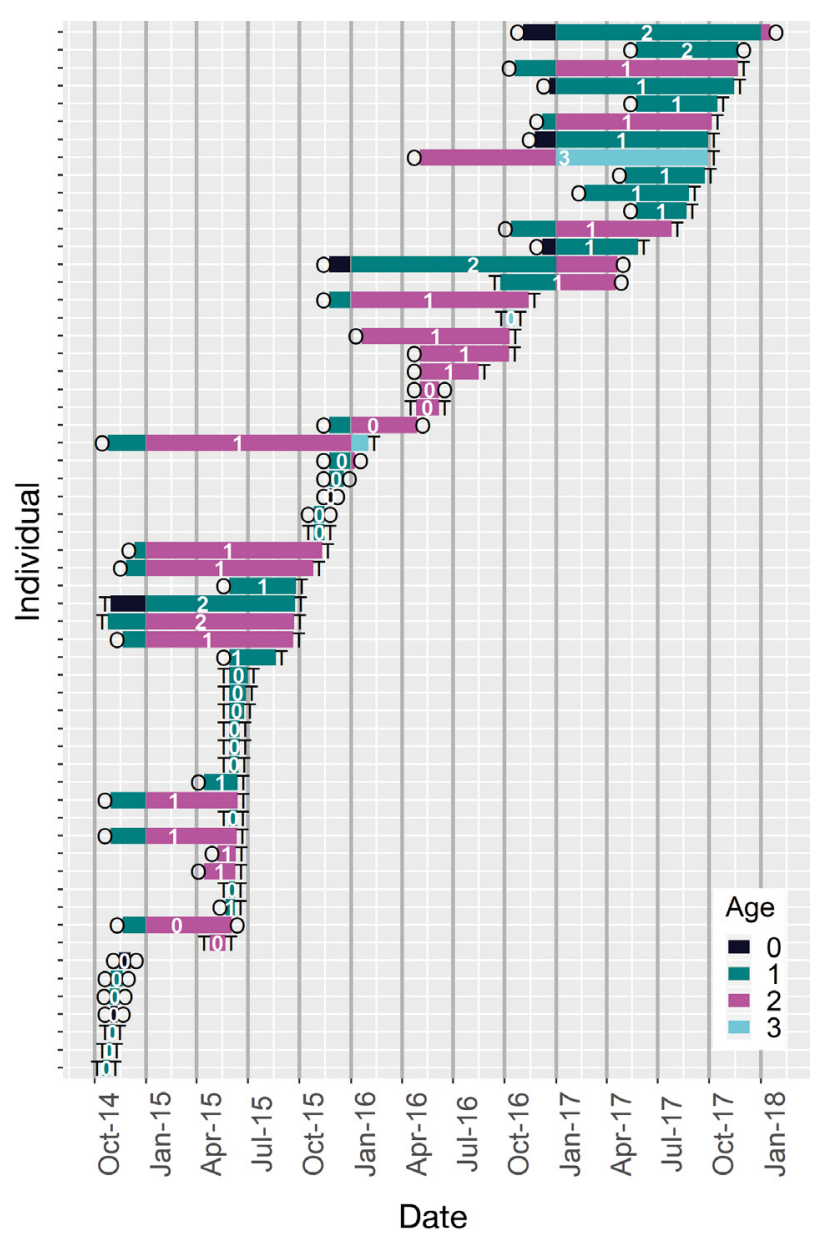

Fig. 9. Age at release and recapture and time at liberty of all recaptured cod for which otoliths and recapture date information were available $(n=59)$. Recapture age was estimated using edge type category at recapture, and previous ages during time at liberty were calculated using time at liberty. The birthday of each cod was assigned as 1 January, following standard age reading protocols. The letters on either end of the bar denote the zone type (O: opaque, T: translucent) at release and recapture. The numbers within the bars indicate the number of zone changes between release and recapture

otoliths is composed of 3 parts: an opaque part formed between January and summer (O1), a TZ formed in summer $(\mathrm{T})$ and another opaque part formed in late autumn (O2). In age- 0 cod, the core area is opaque until the first TZ formed during the first summer and usually displays an opaque edge at the end of the first calendar year. In older cod, O1 merges with $\mathrm{O} 2$ of the previous calendar year, and $\mathrm{O} 2$ merges with $\mathrm{O} 1$ of the next calendar year (Figs. $4 \& 6$, Tables 1 \& 2).

The ages estimated following the guide for juvenile cod indicated that the majority of cod were recaptured at age- $1(n=29)$ or age- $2(n=24)$, with a few individuals recaptured at age- $0(n=3)$ or age- 3 $(\mathrm{n}=3$ ) (Fig. 9). Age at release was calculated from age at recapture by subtracting the time at liberty.

The few recaptures of young adult age- 3 cod provided inconclusive results. Two age-3 recaptures confirmed the TZ formation in summer (Fig. 9) while 1 (cod number 2 in Fig. 4) displayed a translucent instead of the assumed opaque edge type at recapture in February. Given the sequence and proportions of zones, an opaque edge would be expected in this otolith.

Edge type analysis of the otoliths of young adult cod from the 2014-2015 commercial sampling (i.e. not the recaptured individuals) also showed the same zone formation pattern as seen in the recaptured cod otoliths (Fig. S8). However, there were outliers to this pattern present, some otoliths were judged too difficult to classify, and in general, the method was considered relatively subjective.

\section{DISCUSSION}

\subsection{Age validation of western Baltic cod}

This is the first time age estimation of a demersal fish stock in the Baltic Sea has been independently and directly validated using chemical marking of otoliths. Age-validated otolith material was collected for WBC aged 0-3, which encompasses the entire below-minimum-landing-size component of commercial catches ( $\operatorname{cod}<35 \mathrm{~cm}$ total length; age $0-2$ ) and the smaller, though most abundant sizes of the commercial landings (cod from 35-50 cm; ages 2-3) (ICES 2019a).

The timing of TZ formation of age $0-3$ cod, validated through tetracycline marking of otoliths, agreed closely with the timing of TZ formation in age- 0 , age- 1 and age- 2 cod from the same area determined through indirect validation (McQueen et al. 2019a). Our age validation results combined with previously published findings for juvenile WBC (McQueen et al. 2019a) provide robust references with which to eliminate the uncertainties and scientific debates associated with the age estimation of WBC in the past decades (ICES 2005, 2014, 2019b). A high level of agreement in age readings from an otolith exchange exercise in 2019 (ICES 2019a) may be partially linked to the new age validation information available, though age reading inconsistencies were still detected in another recent otolith exchange (ICES 2019b). Issues such as non-standardised otolith preparation techniques between laboratories should also be addressed to ensure consistency in age reading (ICES 2019b). Guidance for age determination of 
age- 0 to age- $3 \mathrm{WBC}$ is given in Table S3. The age reading guide, supported by age-validated material, should facilitate harmonised international age reading activities and increase the reliability of age information used in WBC stock assessment.

Despite the lack of supporting evidence, the TZs in WBC otoliths have routinely been referred to as 'winter rings' in the context of age reading for stock assessments (e.g. ICES 1994, 2000). Given the evidence contrary to this assumption presented here and in other studies (see Section 4.2), the use of this confusing terminology will hopefully be avoided in the future.

\subsection{Formation of TZs during summer}

The timing of TZ formation of age 0-3 WBC coincided with the summer months, generally beginning in late April-June, and ending during SeptemberNovember. TZ formation started and ended slightly earlier in the year than was reported for cod from the western Baltic Sea captured in the 1970s (TZ formation of age 0-2 cod starting in July-September, and ending in December-April, Bingel 1972, 1980). It is possible that earlier TZ formation could be connected to the warming trend in the Baltic Sea (Lehmann et al. 2011), as has been demonstrated for North Sea cod (Pilling et al. 2007, Millner et al. 2011). However, a different methodology (e.g. in otolith processing, microscope), and relatively low sample size, could have influenced the precision of TZ identification by Bingel $(1972,1980)$.

The WBC investigated here inhabit shallower waters and seagrass meadows and experience a pronounced seasonal temperature cycle. In common with other southern cod stocks in the northeast Atlantic, WBC seem to develop the TZ in the summer months when water temperature is at its peak (e.g. Pilling et al. 2007). During peak summer, coastal cod have to respond to unfavourably high water temperatures in shallow waters and low oxygen saturation in deeper waters, which prevent cod from feeding in productive shallow-water habitats (Freitas et al. 2015 , 2016). Instead of moving larger distances to other potentially more favourable coastal areas, cod seem to 'over-summer' locally, displaying strongly reduced up- and down-shore movements and rather stationary behaviour (Freitas et al. 2015, 2016, Funk et al. 2020). Recent stomach analyses in the western Baltic Sea showed that the peak summer months are a period of reduced feeding opportunities for WBC (Funk 2017), and that decreasing temperatures from
October onwards coincide with increased growth rates (McQueen et al. 2019b) and a return to opaque zone formation within the otoliths.

Despite much variation between species and regions, a general pattern has been reported that fish in non-tropical regions form opaque zones within their otoliths during the spring and summer (Beckman \& Wilson 1995). Earlier work reported that this pattern was apparent in North Sea cod (Williams \& Bedford 1974). This consensus probably led to the TZs commonly being referred to as 'winter rings'. However, similarly to the results presented here, several studies have demonstrated using various methods that throughout their range Atlantic cod more commonly deposit translucent material in the otolith during the warmest period of the year. For example, it was revealed using marginal increment analysis that the TZ of North Sea cod is actually deposited during the summer months (Pilling et al. 2007), and the timing of North Sea cod TZ formation occurs earlier in warmer years (Millner et al. 2011). Proportions of translucent edge types in juvenile $\mathrm{WBC}$ were found to correlate positively with increasing water temperatures (McQueen et al. 2019a). Likewise, wild cod caught in southern Norway in the 1930s also developed TZs at the highest seasonal temperature (Dannevig 1956). Analysis of edge type revealed that Skagerrak cod deposit TZs in summer rather than in colder seasons (Otterbech 1953, Gjøsæter \& Danielssen 2011). Stable oxygen isotope analysis has also indicated that the TZ in Atlantic cod otoliths from the Faroe Islands, Irish Sea, North Sea and Barents Sea correspond to the highest seasonal temperatures (Weidman \& Millner 2000). Stable oxygen isotope analysis demonstrated that the TZ formation of North Sea cod and Barents Sea cod occurred in opposing seasons, but as Barents Sea cod tend to migrate northwards to the ice cover during summer, they encounter higher temperatures in winter. Therefore, both stocks appear to follow the pattern of TZ formation during highest seasonal temperatures (Høie et al. 2009). Laboratory experiments have confirmed the relationship between high temperatures and TZ formation in Atlantic cod (Dannevig 1956, Neat et al. 2008).

Despite the consistent correlations between ambient temperature and TZ formation in cod otoliths, water temperature is unlikely to be the only factor influencing the formation of otolith zones (Hüssy et al. 2009, Gronkjær 2016). TZ formation has also been linked to periods of starvation (Hüssy \& Mosegaard 2004, Høie et al. 2008). Pilling et al. (2007) assumed that TZs are formed when the surplus energy (a measure of energy that is needed beyond mainte- 
nance) is lower than a certain threshold. Food limitation therefore is a factor that would decrease the surplus energy below the threshold, especially when coupled with higher water temperatures, when the energy needed for maintenance is also highest. The hypothesis that an interaction between temperature and feeding level explains variation in otolith opacity has been modelled within the framework of the Dynamic Energy Budget, and applying this model to explain zone formation of Barents Sea and North Sea cod otoliths yielded promising results (Fablet et al. 2011).

With the data available from this study, we cannot unequivocally conclude that the deposition of TZs in summer around Fehmarn also applies to other areas in the western Baltic Sea. The recaptured marked cod showed high site fidelity, and the area of recapture is relatively small, thus increasing the risk of a local zone formation mechanism that is caused by the hydro-ecological characteristics of this area. Other areas are deeper (and hence potentially provide a colder summer refuge habitat), which might have an effect on the zone formation. However, many of these deeper areas in the western Baltic are anoxic in summer (e.g. Flensburger Förde, Hansson \& Andersson 2014), which cod avoid (Freitas et al. 2016). Furthermore, since a translucent 'summer ring' also appears in cod of the North Sea (Pilling et al. 2007), Norwegian coast (Dannevig 1956) and Skagerrak (Gjøsæter \& Danielssen 2011) despite their deeper and colder waters, it may be reasonable to assume that the formation of a TZ in summer is characteristic not only for cod in the Belt Sea, but also for other coastal cod populations in this region. Age validation experiments carried out in other regions will be required to test this assumption and, for example, to address the problematic age estimation of eastern Baltic cod (Hüssy et al. 2016).

The coincidence of a validated $\mathrm{TZ}$ formation and observed adverse environmental conditions for cod during peak summer suggests deteriorating conditions for WBC given ongoing warming, heat waves and spreading of hypoxic areas in the future. During this century, temperatures in the Baltic Sea are predicted to continue to rise (Döscher \& Meier 2004, Meier et al. 2006), salinity is predicted to decline (Schrum 2001), and, if external nutrient loads stay the same, eutrophication and oxygen depletion are predicted to increase (Meier et al. 2012). If the volume, depth and duration of hyperthermic shallowwater areas in the western Baltic Sea increase, cod could move deeper, but stratification during summer restricts down-shore movements due to widespread hypoxic areas in the deep regions of the western Baltic (Karlson et al. 2002, HELCOM 2003). Consequently, the period during which cod are restricted to intermediate depths, sandwiched between unfavourably warm water in the shallows and hypoxic deeper water below, will last longer, and cod will potentially have to aggregate in smaller cells of appropriate water conditions (Funk et al. 2020). This may result in negative consequences for cod in these aggregations, such as greater catchability and parasite load, decreased food availability, lower condition or reduced growth, and ultimately in reduced productivity of the stock. Consequently, a validated TZ formation during summer highlights that this period is an eco-physiological bottleneck for WBC that will probably narrow in the future.

\subsection{TZ formation in older cod}

The age-reading guide in Table S3 covers WBC otoliths of age-0 to age-3, though evidence for young adults from our recaptures is not clear-cut because 1 out of 3 age- 3 recaptures was inconclusive (translucent edge in February when an opaque edge was expected). Methods such as otolith edge analysis, which is effective for the age validation of fastgrowing juveniles (Campana 2001, McQueen et al. 2019a), and for which it is easy to obtain large sample sizes from regular sampling activities, become problematic in older fish as the otolith growth rate decreases and edge types become more difficult to interpret. Although the method has apparently proven useful for determining timing of zone formation in older cod from other regions (e.g. Pilling et al. 2007, Gjøsæter \& Danielssen 2011, Millner et al. 2011), McQueen et al. (2019a) highlighted the subjectivity and limitations of applying this approach to older juvenile WBC. We provide a further example of an otolith from an age-1 WBC with an ambiguous edge type in Fig. S2. Likewise, in the otoliths of adult snapper Pagrus auratus, opaque edges are not visible until the subsequent zone has begun to form, resulting in a difference between the time of year when the zone is formed and the time when it becomes detectable (Francis et al. 1992). A similar phenomenon may occur in otoliths of older WBC, and might be exemplified in the 1 out of 3 age- 3 individuals which diverged from the expected pattern of zone formation. This may also explain why 2 individuals at liberty for more than 365 d had only 1 zone change, although this may also be due to slight inter-annual variation in the timing of zone transitions. However, 
with such a low sample size of age- 3 recaptures, it is not possible to determine whether methodological issues or natural variation in the development of these biological structures is the cause of this divergent result.

A preliminary analysis of the edge-types of otoliths from larger WBC $(30-40 \mathrm{~cm})$ indicated that, overall, the results from this method are in agreement with the timing of TZ formation revealed through chemical marking of otoliths, although with some uncertainties, outliers and a degree of subjectivity (Fig. S8). We therefore conclude that although otolith edge analysis can be useful, the results should be interpreted with caution, and should at least not be relied on as the only method for analysis of otoliths from older cod. Using this method in combination with analysis of the release zone types in a chemical marking experiment allows the results to be interpreted with more confidence.

It has been reported for cod in other regions that the otolith zone formation may alter once individuals commence spawning (Smedstad \& Holm 1996, Weidman \& Millner 2000, Hüssy et al. 2009). More recently, Irgens et al. (2020) demonstrated through laboratory experiments that spawning does not directly influence zone formation in cod, although it cannot be ruled out that the cost of spawning migrations, changes in food availability and environmental conditions associated with spawning have an effect on otolith growth and opacity (Irgens et al. 2020). The majority of recaptures from our study were classified as stage II on the maturity scale. Stage II individuals may be virgin, can occur throughout the year and will not necessarily contribute to spawning in the following season (Tomkiewicz et al. 2003). The few recaptures in our study which had already begun spawning (mostly recaptured cod of age-2 and age3) did not show evidence of a change in TZ formation patterns. Surface-to-volume ratio principles postulate that large cod experience problems with oxygen supply at lower temperatures than smaller cod (Pörtner et al. 2008, Pauly 2010), with optimal temperature for growth decreasing as body size increases (Björnsson \& Steinarsson 2002). Hence, if juvenile and young adult cod form a TZ in response to high summer temperature, it follows that older adults should also. Larger cod may partly alleviate the temperature stress by (micro-)habitat choice in summer (Freitas et al. 2015, 2016), but they cannot totally escape the seasonal temperature cycle. Therefore, given our results and the assumed drivers of zone formation in cod otoliths, we hypothe- sise that it is likely that the $\mathrm{TZ}$ formation in summer occurs in both younger and older adult cod. Ultimately, our results for young adults are preliminary and need to be confirmed.

\subsection{Practical considerations of age validation studies}

An age validation method such as the chemical marking of otoliths should be preferentially used for older age classes of a population (Campana 2001), and recaptures of mature fish are therefore especially valuable. This suggests that tagging programmes for age validation should ab initio release both marked juveniles and adults covering a wide size range to increase the probability of recaptures of older fish. In this tagging study, we took advantage of access to a supply of bycaught small cod from commercial fishers. A tagging scheme targeting large, market-sized individuals may have to rely on an independent source of fish, or provide compensation to the fishers.

Despite very low return rates of tagged cod, our study demonstrated that through cooperation with local fishers, an effective tagging programme is achievable through relatively low effort and expense. Due to the mostly consistent pattern apparent within the recaptured cod otoliths, in this study a low return rate was sufficient to validate the timing and frequency of $\mathrm{TZ}$ formation in the most relevant age classes of WBC within a relatively short time period. To ensure recaptures, age validation experiments should be conducted in areas with a high fishing pressure and combined with awareness programmes that also include recreational fisheries like angling. In the case of the $\mathrm{WBC}$, anglers are a large resource user group (Strehlow et al. 2012). However, the return rate was still considerably lower than the recapture rates of $12-42 \%$ achieved in cod tagging experiments carried out in the western Baltic Sea in the 1950s, 60s and 70s (Thurow 1963, Berner 1968, 1969, 1973). A large proportion of recaptures were returned by participants in the tagging project, similarly to another more recent cod tagging experiment in the western Baltic Sea (McQueen et al. 2019b). This indicates that the active involvement and participation of fishers and anglers in present-day tagging activities can still be greatly improved.

The need for validated age estimation of otoliths is increasing, as the systematic collection of otoliths from commercial fisheries (e.g. in the context of the European Data Collection Framework) has resulted in usable time series and increased data quality. 
These data are used to enhance the ICES stock assessment. From over 260 stocks that are currently managed by the International Council for the Exploration of the Sea (ICES), about $35 \%$ are evaluated by an analytical assessment and another $40 \%$ by agebased explorative assessments and/or age-based biological parameters (e.g. maturity and mortality) (ICES 2016), but only a minor part uses otoliths with validated age estimation.

\section{CONCLUSION}

The age validation experiments conducted on juvenile cod from the western Baltic Sea verified that the TZ within otoliths is laid down in summer and not, as previously assumed, in winter. This pattern, found in several nearby cod stocks in the wild, suggests that it may also be characteristic for other cod populations in the North Sea, Skagerrak or Kattegat.

The chemically validated understanding of $\mathrm{TZ}$ formation during summer provides a time stamp in otoliths that can better guide ecological studies, has a direct impact on how age is estimated from the otolith, and hence can improve the quality of the stock assessment.

The conducted age validation experiments are likely feasible for many demersal nearshore fish species and stocks for which small-scale fishers can provide live fish in larger quantities. The application of tetracycline as a chemical otolith marker provided clear marks on the otoliths of the released/ recaptured cod and thus has proven its feasibility for mark-and-release studies of cod.

Acknowledgements. We thank U. Fröse for providing the live cod, and the harbour chief of Burg auf Fehmarn for the cooperation during the experiments. We are grateful to all Thünen-OF staff members involved in tagging cod, in particular to T. Rohde, I. Hennings and G. Basedow for conducting the majority of the work involved in tagging and processing of recaptures, and to I. Hennings for the microscopy work. Thanks to A. Schütz for helping with the photoediting. We also thank all fishers and anglers who returned recaptured cod. Comments of 3 anonymous reviewers helped to improve the manuscript. The experiment was conducted under the animal test permission of SchleswigHolstein V 244 - 7224.121.9-6 (84-6/14). U.K., S.S., K.M. and this mark-recapture study were co-funded by the European Commission's Data Collection Framework. K.M. was also funded by BalticSea2020 (http://balticsea2020.org) through the project 'Tagging Baltic Cod' (TABACOD). This study is in part based on doctoral dissertations by S. Stötera (2017) and K. McQueen (2019) at the University of Hamburg, Germany.

\section{LITERATURE CITED}

Beamish RJ, McFarlane GA (1983) The forgotten requirement for age validation in fisheries biology. Trans Am Fish Soc 112:735-743

Beckman D, Wilson CA (1995) Seasonal timing of opaque zone formation in fish otoliths. In: Secor DH, Dean JM, Campana SE (eds) Recent developments in fish otolith research. University of South Carolina Press, Columbia, SC, p 27-43

Berner M (1968) Dorschmarkierungen in der Mecklenburger Bucht im Jahre 1965. Fisch-Forsch 6:73-76

Berner M (1969) Ergebnisse der Dorschmarkierungen des Jahres 1967 in der Arkonasee und der Mecklenburger Bucht. Fisch-Forsch 7:39-43

Berner M (1973) Ergebnisse der Dorschmarkierungen des Jahres 1970 in der Mecklenburger Bucht. Fisch-Forsch 11:19-25

Bingel F (1972) Zur Interpretation von Otolithenstrukturen des Dorsches (Gadus morhua L.). Diploma thesis, University of Kiel

Bingel F (1980) Identifikation von Strukturen in Otolithen des Dorsches (Gadus morhua) der Kieler Bucht. Meeresforsch Rep Mar Res 28:69-74

Björnsson B, Steinarsson A (2002) The food-unlimited growth rate of Atlantic cod (Gadus morhua). Can J Fish Aquat Sci 59:494-502

Björnsson B, Steinarsson A, Árnason T (2007) Growth model for Atlantic cod (Gadus morhua): effects of temperature and body weight on growth rate. Aquaculture 271:216-226

Blanchard JL, Mills C, Jennings S, Fox CJ, Rackham BD, Eastwood PD (2005) Distribution-abundance relationships for North Sea Atlantic cod (Gadus morhua): observation versus theory. Can J Fish Aquat Sci 59:494-502

* Burrows MT, Gibson RN, Robb L, Comely CA (1994) Temporal patterns of movement in juvenile flatfishes and their predators: underwater television observations. J Exp Mar Biol Ecol 177:251-268

Campana SE (2001) Accuracy, precision and quality control in age determination, including a review of the use and abuse of age validation methods. J Fish Biol 59:197-242

Campana SE, Thorrold SR (2001) Otoliths, increments and elements: keys to a comprehensive understanding of fish populations? Can J Fish Aquat Sci 58:30-38

Dannevig A (1956) The influence of temperature on the formation of zones in scales and otoliths of young cod. Fiskeridir Skr (Havunders) 11:3-16

de Pontual H, Groison AL, Piñeiro C, Bertignac M (2006) Evidence of underestimation of European hake growth in the Bay of Biscay, and its relationship with bias in the agreed method of age estimation. ICES J Mar Sci 63: 1674-1681

* Döscher R, Meier HEM (2004) Simulated sea surface temperature and heat fluxes in different climates of the Baltic Sea. Ambio 33:242-248

Drinkwater KF (2005) The response of Atlantic cod (Gadus morhua) to future climate change. ICES J Mar Sci 62: 1327-1337

Eero M, Hjelm J, Behrens J, Buchmann K and others (2015) Eastern Baltic cod in distress: biological changes and challenges for stock assessment. ICES J Mar Sci 72: 2180-2186

F Fablet R, Pewcquerie L, de Pontual H, Høie H, Millner R, Mosegaard H, Kooijman SALM (2011) Shedding light on fish otolith biomineralization using a bioenergetic approach. PLOS ONE 6:e27055 
Francis MP, Williams MW, Pryce AC, Pollard S, Scott SG (1992) Daily increments in otoliths of juvenile snapper, Pagrus auratus (Sparidae). Aust J Mar Freshw Res 43:1015-1032

Freitas C, Olsen EM, Moland E, Ciannelli L, Knutsen H (2015) Behavioral responses of Atlantic cod to sea temperature changes. Ecol Evol 5:2070-2083

Freitas C, Olsen EM, Knutsen H, Albresten J, Moland E (2016) Temperature-associated habitat selection in a cold-water marine fish. J Anim Ecol 85:628-637

Funk S (2017) Depth-specific patterns in distribution and food intake of cod (Gadus morhua) in the western Baltic Sea. MSc thesis, University of Hamburg

Funk S, Krumme U, Temming A, Möllmann C (2020) Gillnet fishers' knowledge reveals seasonality in depth and habitat use of cod (Gadus morhua) in the Western Baltic Sea. ICES J Mar Sci, doi:10.1093/icesjms/fsaa071

* Gjøsæter J, Danielssen DS (2011) Age, growth and otolith annulus formation of cod (Gadus morhua) in the Risør area on the Norwegian Skagerrak coast during 1986-1996. Mar Biol Res 7:281-288

Gronkjær P (2016) Otoliths as individual indicators: a reappraisal of the link between fish physiology and otolith characteristics. Mar Freshw Res 67:881-888

Hansson M, Andersson L (2014) Oxygen survey in the Baltic 2014: extent of anoxia and hypoxia, 1960-2014. Rep Oceanogr 50, Swedish Meteorological and Hydrological Institute, Göteborg. https://www.smhi.se/polopoly_fs/ 1.83639!/Menu/general/extGroup/attachmentColHold/ mainCol1/file/RO_50.pdf

HELCOM (2003) The 2002 oxygen depletion event in the Kattegat, Belt Sea and Western Baltic. Balt Sea Environ Proc No 90. HELCOM, Helsinki

* Hemmer-Hansen J, Hüssy K, Baktoft H, Huwer B and others (2019) Genetic analyses reveal complex dynamics within a marine fish management area. Evol Appl 12: 830-844

Høie H, Folkvord A (2006) Estimating the timing of growth rings in Atlantic cod otoliths using stable oxygen isotopes. J Fish Biol 68:826-837

Høie H, Folkvord A, Mosegaard H, Li L, Clausen LAW, Norberg B, Geffen AJ (2008) Restricted fish feeding reduces cod otolith opacity. J Appl Ichthyol 24:138-143

Høie H, Millner RS, McCully S, Nedreaas KH, Pilling GM, Skadal J (2009) Latitudinal differences in the timing of otolith growth: a comparison between the Barents Sea and southern North Sea. Fish Res 96:319-322

*Hüssy K, Mosegaard H (2004) Atlantic cod (Gadus morhua) growth and otolith accretion characteristics modelled in a bioenergetics context. Can J Fish Aquat Sci 61: 1021-1031

* Hüssy K, Nielsen B, Mosegaard H, Clausen LW (2009) Using data storage tags to link otolith macro-structure in Baltic cod Gadus morhua with environmental conditions. Mar Ecol Prog Ser 378:161-170

* Hüssy K, Radtke K, Plikshs M, Oeberst R and others (2016) Challenging ICES age estimation protocols: lessons learned from the eastern Baltic cod stock. ICES J Mar Sci 73:2138-2149

ICES (1994) Report of the workshop on Baltic cod age reading, 6-10 June 1994, Gdynia, Poland. ICES CM 1994/J:5

ICES (2000) Study group on Baltic cod age reading, 27-31 March 2000, Karlskrona, Sweden. ICES CM 2000/H:01

ICES (2005) Report of the study group on ageing issues of Baltic cod (SGABC), 17-20 May 2005, Klaipeda, Lithuania. ICES CM 2006/ACFM:02
ICES (2014) Report of the workshop on scoping for integrated Baltic cod assessment (WKSIBCA), 1-3 October 2014, Gdynia, Poland. ICES CM 2014/ACOM:62

ICES (2016) Report of the ICES Workshop on the Development of Quantitative Assessment Methodologies based on life-history traits, exploitation characteristics, and other relevant parameters for stocks in categories 3-6 (WKLIFEVI). 3-6 October 2016, Lisbon, Portugal

ICES (2019a) Baltic Fisheries Assessment Working Group (WGBFAS). ICES Sci Rep 1:20

ICES (2019b) Report of the Benchmark Workshop on Baltic Cod Stocks (WKBALTCOD2). ICES Sci Rep 1:9

ICES (2019c) Cod (Gadus morhua) in subdivisions 22-24, western Baltic stock (western Baltic Sea). In: Report of the ICES Advisory Committee, 2019, cod.27.22-24

* Irgens C, Folkvord A, Otterå H, Kjesbu OS (2020) Otolith growth and zone formation during first maturity and spawning of Atlantic cod (Gadus morhua). Can J Fish Aquat Sci 77:113-123

Jobling M (1988) A review of the physiological and nutritional energetics of cod, Gadus morhua L., with particular reference to growth under farmed conditions. Aquaculture 70:1-19

Kalish JM, Beamish RJ, Brothers EB, Casselman JM and others (1995) Glossary for otolith studies. In: Secor DH, Dean JM, Campana SE (eds) Recent developments in fish otolith research. University of South Carolina Press, Columbia, SC, p 723-729

Karlson K, Rosenberg R, Bonsdorff E (2002) Temporal and spatial large-scale effects of eutrophication and oxygen deficiency on benthic fauna in Scandinavian and Baltic waters-a review. Oceanogr Mar Biol Annu Rev 40: $427-489$

Krumme U, Bingel F (2016) Tetracycline marks visible in Baltic cod Gadus morhua otoliths stored for 40 years. J Fish Biol 89:2189-2194

Kullenberg G, Jacobsen TS (1981) The Baltic Sea: an outline of its physical oceanography. Mar Pollut Bull 12:183-186

* Lehmann A, Getzlaff K, Harlaß J (2011) Detailed assessment of climate variability in the Baltic Sea area for the period 1958 to 2009. Clim Res 46:185-196

*McQueen K, Hrabowski J, Krumme U (2019a) Age validation of juvenile cod in the western Baltic Sea. ICES J Mar Sci 76:430-441

* McQueen K, Eveson JP, Dolk B, Lorenz T, Mohr T, Schade FM, Krumme U (2019b) Growth of cod (Gadus morhua) in the western Baltic Sea: estimating improved growth parameters from tag-recapture data. Can J Fish Aquat Sci 76:1326-1337

Meier HEM, Feistel R, Piechura J, Arneborg L and others (2006) Ventilation of the Baltic Sea deep water: a brief review of present knowledge from observations and models. Oceanologia 48:133-164

*Meier HEM, Andersson HC, Arheimer B, Blenckner T and others (2012) Comparing reconstructed past variations and future projections of the Baltic Sea ecosystem - first results from multi-model ensemble simulations. Environ Res Lett 7:034005

* Millner RS, Pilling GM, McCully S, Høie H (2011) Changes in the timing of otolith zone formation in North Sea cod from otolith records: an early indicator of climateinduced temperature stress? Mar Biol 158:21-30

Neat FC, Wright P, Fryer RJ (2008) Temperature effects on otolith pattern formation in Atlantic cod Gadus morhua. J Fish Biol 73:2527-2541 
Otterbech F (1953) The cod population of the Oslofjord. Rapp P-V Reùn Cons Int Explor Mer 136:15-21

Panfili J, de Pontual H, Troadec H, Wright PJ (2002) Manual of fish sclerochronology. Ifremer-lRD coedition, Brest

Pannella G (1974) Otolith growth patterns: an aid in age determination in temperate and tropical fishes. In: Bagenal TB (ed) The ageing of fish. Unwin Brothers Ltd, The Gresham Press, Surrey, p 28-39

Pauly D (2010) Gasping fish and panting squids: oxygen, temperature and the growth of water-breathing animals. Excellence in ecology, Book 22. International Ecology Institute, Oldendorf/Luhe

Pilling GM, Millner RS, Easey MW, Maxwell DL, Tidd AN (2007) Phenology and North Sea cod Gadus morhua L.: Has climate change affected otolith annulus formation and growth? J Fish Biol 70:584-599

Pörtner HO, Bock C, Knust R, Lannig G, Lucassen M, Mark FC, Sartoris FJ (2008) Cod and climate in a latitudinal cline: physiological analyses of climate effects in marine fishes. Clim Res 37:253-270

Righton DA, Andersen KH, Neat F, Thorsteinsson V and others (2010) Thermal niche of Atlantic cod Gadus morhua: limits, tolerance and optima. Mar Ecol Prog Ser 420:1-13

Robichaud D, Rose GA (2004) Migratory behaviour and range in Atlantic cod: inference from a century of tagging. Fish Fish 5:185-214

Schrum C (2001) Regionalization of climate change for the North Sea and Baltic Sea. Clim Res 18:31-37

Siegel H, Gerth M (2015) Sea surface temperature in the Baltic Sea in 2015. HELCOM Baltic Sea Environmental Fact Sheet. www.helcom.fi/baltic-sea-trends/environmentfact-sheets/ (accessed 30 Jun 2017)

Editorial responsibility: Stylianos Somarakis, Heraklion, Greece
Smedstad OM, Holm JC (1996) Validation of back-calculation formulae for cod otoliths. J Fish Biol 49:973-985

* Stötera S, Krumme U (2016) Use of otolith quality flags to assess distributional dynamics in Baltic cod stocks. Mar Freshw Res 67:980-991

* Stötera S, Degen-Smyrek AK, Krumme U, Stepputtis D, Bauer R, Limmer B, Hammer C (2019) Marking otoliths of Baltic cod (Gadus morhua Linnaeus, 1758) with tetracycline and strontium chloride. J Appl Ichthyol 35:427-435

* Strehlow HV, Schultz N, Zimmermann C, Hammer C (2012) Cod catches taken by the German recreational fishery in the western Baltic Sea, 2005-2010: implications for stock assessment and management. ICES J Mar Sci 69: 1769-1780

Thurow F (1963) Dorschmarkierungen in der westlichen Ostsee. Inf Fischwirtsch 10:12-17

* Tomkiewicz J, Tybjerg L, Jespersen A (2003) Micro- and macroscopic characteristics to stage gonadal maturation of female Baltic cod. J Fish Biol 62:253-275

* Weidman CR, Millner R (2000) High-resolution stable isotope records from North Atlantic cod. Fish Res 46:327-342

*Weist P, Schade FM, Damerau M, Barth JMI and others (2019) Assessing SNP-markers to study population mixing and ecological adaptation in Baltic cod. PLOS ONE 14:e0218127

*Williams AJ, Davies CR, Mapstone BD (2005) Variations in the periodicity and timing of increment formation in red throat emperor (Lethrinus miniatus) otoliths. Mar Freshw Res 56:529-538

Williams T, Bedford BC (1974) The use of otoliths for age determination. In: Bagenal TB (ed) The ageing of fish. Unwin Brothers Ltd, The Gresham Press, Surrey, p 114-123

Submitted: June 4, 2019; Accepted: May 28, 2020

Proofs received from author(s): June 26, 2020 